\title{
Review and Evaluation of the State of the Art of DC Fault Detection for HVDC Grids
}

\author{
Vasileios Psaras \\ Dept. of Elec. Engineering \\ University of Strathclyde \\ Glasgow, UK \\ vasileios.psaras@strath.ac.uk \\ Abdullah Emhemed \\ Dept. of Elec. Engineering \\ University of Strathclyde \\ Glasgow, UK \\ abdullah.emhemed@strath.ac.uk
}

\author{
Grain Adam \\ Dept. of Elec. Engineering \\ University of Strathclyde \\ Glasgow, UK \\ grain.adam@strath.ac.uk
}

\author{
Graeme Burt \\ Dept. of Elec. Engineering \\ University of Strathclyde \\ Glasgow, UK \\ graeme.burt@strath.ac.uk
}

\begin{abstract}
This paper reviews the state of the art of DC fault discrimination and detection methods of HVDC grids, and summarises the underlying principles and the characteristics of each method. To minimize HVDC grid disturbance and power transfer interruption due to DC faults, it is critically important to have protection schemes that can detect, discriminate and isolate DC faults at high speeds with full selectivity. On this basis, this paper lists the advantages and disadvantages of the most promising fault detection methods, with the aim of articulating the future directions of HVDC protection systems. From the qualitative comparison of relative merits, the initial recommendations on HVDC grid protection are presented. Moreover, a comprehensive quantitative assessments of different fault detection methods discussed above are carried out on a generic 4-terminal meshed HVDC grid, which is modelled in PSCAD environment. The presented simulation results identify that the voltage derivative and wavelet transform are the most promising methods for DC fault detection and discrimination.
\end{abstract}

Index Terms-Fault detection, HVDC grids, Protection systems, Voltage-source converter (VSC) technology

\section{INTRODUCTION}

High-Voltage Direct Current (HVDC) transmission system technology has proven to be a viable economic solution for the interconnection of renewables in remote areas to the AC grids. Among others, HVDC technology facilitates bulk power transmission over long distances with high reliability and offers the capability to interconnect asynchronous AC networks, and greater stability benefits and controllability that may allow connection to weak AC networks [1], [2].As a result, HVDC transmission is the preferred option for connecting offshore wind farms to the mainland AC grids. With constant growth in the number and capacity of installed offshore farms, a meshed DC grid offers a cost effective solution for connection of multiple wind farms, with multiple HVDC links between the system DC nodes and multiple connections to the mainland AC grids in the vicinity of the HVDC grid [3], [4].

The major challenge in practical realisation of HVDC networks is the DC fault protection solutions. This challenge is driven by the fact that DC faults can propagate very quickly over the network and the resulting fault currents increase rapidly. For point-to-point HVDC links, the typical protection method is to open the AC circuit breakers at both ends of the link [3]. Application of the same method to HVDC networks, would lead to the shutdown of the entire network for relatively long time (few hundred milliseconds). This would pose a serious threat to the operation of the $\mathrm{AC}$ network and might also compromise the total system stability [5]. To avoid such issues, DC circuit breakers are required to isolate the faulted lines and keep the rest of the network operational. Placement of sizeable DC inductors in series with the DC circuit breakers is one of the practical steps that have been adopted to slowdown the rate of rise of the fault current, thus allowing the breakers to act within their time window before the maximum current breaking capability is exceeded. Therefore, a protection system must detect every probable fault quickly and identify the faulted part with the aim of minimising the DC network disturbance. However, the timeframes for fault isolation remain within several milliseconds, depending on the type of DC circuit breakers being employed. Consequently, speed and selectivity are two of the most important requirements for DC protection systems, and for the design of the fault detection and discrimination algorithms to be implemented [3], [6]

Therefore, this paper aims to investigate the most effective fault detection methods and their selectivity capabilities. In doing so, a review of the state of the art of DC fault detection is carried out and the most competitive and promising methods are selected for further evaluation, with focus on their suitability for use as a main protection system for HVDC grids. The paper is structured as follows: section II provides an overview of DC fault detection methods with Section III summarising their advantages and disadvantages. Section IV describes the 4-terminal meshed HVDC grid, which is modelled in PSCAD and subsequently used in Section V in quantitative assessments of the two most promising fault detection methods. Finally, conclusions are drawn in section VI.

\section{DC FAult Detection}

This section reviews the principles of a number of DC fault detection methods applied to HVDC grids. Generally, DC fault detection methods can be classified into single-ended and double-ended, with the former relying on local measurements exclusively, and the latter on local measurements in conjunction with remote measurements from the other end of the line; both are using the measurements with the aim to reach a decision about the location of the fault and about whether it is their responsibility to act or not. The main 
challenge of double-ended fault detection is that it relies on a communication link to receive signal measurements from the other end of the line, which causes problems of reliability and delay in its response time. For short lines, this might not be a significant issue. However, in a large-scale meshed HVDC grid, with considerably long lines, the performance of twoended methods deteriorates due to the longer propagation time of the signals to be measured from the remote end [3].

Alternatively, fault detection methods can be classified into unit protection and non-unit protection. Non-unit protection techniques usually rely on the placement of inductors at each end of each line to define the protection boundaries [7]. Moreover, the series inductor serves as the current limiter that restraints the rate of rise of the fault current $(d i / d t)$. Conversely, unit-protection methods such as current differential or directional protection do not rely on series inductors. In principle, two-ended fault detection methods are also unit protection methods, where the protection zones are clearly defined.

The above methods are considered selective approaches to DC protection. Partially-selective approaches have been proposed, in which the HVDC grid is divided into protection zones. When a fault happens inside a predefined zone, the whole affected zone is disconnected using DC circuit breakers or other devices such as DC-DC converters at well-defined locations, allowing the remaining healthy zones to continue to operate normally [8], [9]. This approach is effective for small HVDC grids, and it can divide a large complex HVDC grid into smaller manageable parts. However, its adaption is more challenging in large HVDC grids with high power ratings, where minimum grid disturbance is required. Non-selective approaches usually involve the use of fault tolerant converters or AC breakers in the same manner as protecting a pointto-point HVDC link. However, these protection philosophies fall outside of the scope of the current study, where the considered DC protection methods are aimed to be fully selective with clearly defined zones. The rest of this section presents the principles of unit and non-unit fault detection methods. However, it should be noted that in practice, the implementation of complete primary DC protection schemes usually involves a combination of different fault detection submethods that complement each other.

\section{A. Unit Protection}

1) Current Differential: Current differential is considered as a unit protection method, where the protected unit can be a busbar, a converter station or a DC line. For DC lines, this method can be implemented with the use of relays at both ends of the protected unit. Each relay measures the local current and communicates the measured value to the other end of the line. In this way, each relay possesses the current values of both ends and compares their difference against a predefined threshold. The result of this comparison is called differential currentand when this exceeds the threshold, a fault is detected.

Current differential is a very robust method and offers very good selectivity and directionality. However, it has some drawbacks, for example, the use of signals from both terminals implies the necessity for a communication link. Communication adds a degree of reliability requirements, and time delay and synchronisation challenges, Thus, each relay has to compensate for the time delay caused by the communication link in order to retrieve the value of the current at the time of interest. The need for accurate timestamped data from both ends complicates the method further. Communication time delays can be even larger for longer lines, and therefore, the use of current differential protection in the HVDC grid with long DC lines might be unacceptable. The problem is further exacerbated, when the fault happens near to one of the terminals, because in this case the time delay will be the longest. However, current differential is a good choice for a system with shorter DC lines. Finally, current differential is an appropriate means of busbar protection, where the difference between outcoming and incoming currents is measured and if it is non-zero, a fault is detected inside the substation [3].

2) Directional Protection: Directional protection is another communication-based method. In this case, each relay communicates only the direction of the current to the other end when a fault is detected. If the relays of the protected line identify a fault in their respective forward direction, a trip command is generated, and the line is isolated. Owing to the simplicity of the transmitted information (i.e. sign of the current), the method is more robust than the current differential method [3]. However, this kind of protection suffers from the same limitations caused by the time delay of the communication scheme and the transmission issues.

\section{B. Non-unit Protection}

1) Overcurrent and Undervoltage: Overcurrent is the simplest method used for fault detection, in which current measurements are used at a single terminal, and is usually based on a time graded characteristic [1]. This is the method behind the protection philosophy of IGBTs of VSCs. Typically, this method uses a current threshold, which if exceeded, a fault is detected. Simply by monitoring the polarity of the current, directionality is ensured owing to the constant DC voltage. However, selectivity cannot be achieved through this method since both internal and external faults (with respect to the protected line) may cause high fault currents. Therefore, this method is mostly used as back-up protection or in combination with other methods to form a complete protection scheme.

Faults are characterised by very low voltages, and as a result, under-voltage relays can provide an indication that a fault has happened. Similarly, a voltage threshold is set and when the measured voltage drops below the threshold, a fault is detected. Similar to overcurrent detection, under-voltage does not distinguish between forwards and backwards faults (thus, directionality is not achieved). Also, this method can be used as a back-up protection or as one of the fault detection criteria of a complete protection scheme.

2) Travelling-wave-based Techniques: According to traveling wave theory, when a fault occurs, voltage and current waves are generated and propagate rapidly through the DC lines of the entire HVDC network. There is a significant 
amount of information contained in the initial voltage and current surges that propagate from the point of the fault to the ends of the line. Travelling-wave based methods attempt to capture that information to detect a fault and act against it. The principle of the method, is to detect the initial wave front [10]. Towards this aim, voltage and currents are measured continuously at a high sampling frequency. Then, the difference between two measurements is calculated, and if it exceeds a predefined threshold, then the result is saved. Subsequently, the magnitude of the next samples is reported and compared in order to determine if the wave magnitude continues to exceed that threshold within a specified time interval. If all the samples demonstrate that the successive measured magnitudes are higher than the specified threshold, then a fault is detected. On the downside, for long DC lines, the magnitude of the waves is largely attenuated hence, the performance of the detection method can be compromised.

3) Voltage and Current Derivative: Voltage derivative or simply $d v / d t$ has been widely used in Line-commutated Converter-based (LCC) HVDC point-to-point transmission [11]. The principle is the same as in under-voltage method, but the derivative of the voltage is used instead. The rate of the change of the voltage is measured at fixed time intervals. This method has the advantage of being very fast, because it is based on the first incident wave, which allows for a quick detection [10]. However, the method is affected by the length of the line and the selectivity is limited by the low cable impedance. The current derivative, di/dt, method uses the initial rate of rise of fault current to determine whether or not a fault has occurred on the protected line. The principle is the same as in overcurrent method, but the magnitude of the derivative of the current is used instead. However, the method is susceptible to noise and might suffer from the collection of incorrect data samples [12]. Moreover, $d i / d t$ for remote internal faults with large fault resistance may be lower than $d i / d t$ for external faults [13].

4) Wavelet Transform: Travelling wave-based techniques have been further refined and improved through means of signal processing [14]. These methods are still based on voltage and current measurements but employ mathematical tools such as Fourier analysis. A common signal processing method is the Fourier Transform (FT), but it requires information about the monitored signal for an extensive period of time, making it inappropriate for fault detection. Moreover, FT loses significant information about the signal and any singularities that may appear. The introduction of wavelet analysis can overcome these problems.

Wavelet analysis is a powerful signal processing tool that can be useful for fault detection purposes. It is worth noting that wavelet analysis does not work on a time-frequency basis, but rather on a time-scale basis [15]. This tool can detect abrupt, local changes in a signal such as the current transients after a fault. Towards this aim, the Wavelet Transform (WT) is employed. Therefore, the first local minimum or maximum of wavelet transform coefficients of a fault current can provide an indication of an underlying fault.
WT decomposes the examined signals over translated and dilated wavelets. A wavelet is defined as a function $(\psi)$ with a zero average. In particular, WT is characterised by a dilation parameter $(\alpha)$ and a translation parameter $(b)$. The dilation parameter determines the size of the window in which the transform is performed. The translation parameter determines the time corresponding to the centre point of each time window [15]. The wavelet transform of a signal $u(t)$ with scale at time $t$ is calculated through the following formula:

$$
W T_{(\alpha, b)} u(t)=\int_{-\infty}^{\infty} u(t) \frac{1}{\sqrt{\alpha}} \psi^{*}\left(\frac{t-b}{\alpha}\right) d t
$$

Where $\psi^{*}$ is the daughter wavelet that is a scaled and shifted version of the mother wavelet function $\psi$. Fig. 1 illustrates two common types of mother wavelets. The appropriate mother wavelet is usually chosen through trial and error studies [16]. In general, there are two types of the wavelet transform: Continuous Wavelet Transform (CWT) and Discrete Wavelet Transform (DWT). CWT requires a large computation time and is therefore avoided in HVDC fault detection applications, while it is preferred in fault location applications. On the contrary, DWT requires less computation time and is usually preferred for fault detection application. With the use of DWT, the measured signal is passed through successive layers of low-pass and high-pass filters and each layer produces a low frequency approximation (A) and a high frequency detailed (D) coefficient respectively. When the DWT is used for DC fault detection, the most appropriate level and its associated coefficients are determined through various simulations.

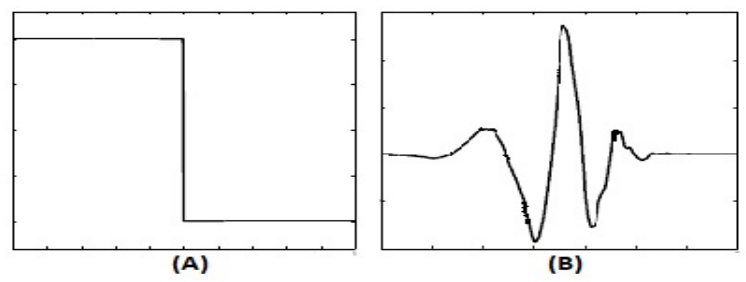

Fig. 1: Two common mother wavelets, (A) Haar wavelet and (B) Daubechies wavelet.

\section{Summary of Detection Methods and Discussion}

The characteristics, the advantages and disadvantages of the fault detection methods are summarised in Table 2. Unit protection methods offer inherent selectivity as the protection zones are well defined. Protection systems have been designed based on the current differential and the directional protection methods [10], [17]. However, these protection systems rely on a communication link in order to obtain signal measurements from the other end of the line. Therefore, the technical feasibility of these methods is greatly compromised in large HVDC grids with lines of several hundreds of kilometres. For instance, for a two hundred kilometres transmission line, the signal propagation time is around $1 \mathrm{~ms}$ though fibre optic cable [18]. Considering that the rise of a fault current is in the range of a few $\mathrm{kA}$ per ms, this time delay cannot be neglected. In the twenties project, it was suggested that the upper limit for 
TABLE I. COMPARISON OF DIFFERENT DC FAULT DETECTION METHODS

\begin{tabular}{|c|c|c|c|c|c|c|c|c|}
\hline Method & Overcurrent & Undervoltage & $\begin{array}{c}\text { Travelling } \\
\text { waves }\end{array}$ & dv/dt & $\mathrm{di} / \mathrm{dt}$ & $\begin{array}{c}\text { Current } \\
\text { differential }\end{array}$ & $\begin{array}{c}\text { Directional } \\
\text { protection }\end{array}$ & $\begin{array}{c}\text { Wavelet } \\
\text { Transform }\end{array}$ \\
\hline $\begin{array}{l}\text { Use of } \\
\text { reactor }\end{array}$ & $\begin{array}{l}\text { Reactor is } \\
\text { used to limit } \\
\text { fault current }\end{array}$ & $\begin{array}{l}\text { Reactor is } \\
\text { used for } \\
\text { selectivity }\end{array}$ & $\begin{array}{l}\text { Reactor is } \\
\text { used to define } \\
\text { boundaries }\end{array}$ & $\begin{array}{l}\text { Reactor is } \\
\text { used to define } \\
\text { boundaries }\end{array}$ & $\begin{array}{l}\text { Reactor is } \\
\text { used to define } \\
\text { boundaries }\end{array}$ & Not needed & Not needed & $\begin{array}{l}\text { Reactor is } \\
\text { used to define } \\
\text { boundaries }\end{array}$ \\
\hline $\begin{array}{l}\text { Use of } \\
\text { comms }\end{array}$ & $\mathrm{NO}$ & NO & NO & NO & $\mathrm{NO}$ & YES & YES & NO \\
\hline $\begin{array}{c}\text { Main/backup } \\
\text { protection }\end{array}$ & $\begin{array}{l}\text { Part of main } \\
\text { protection } \\
\text { OR Back-up } \\
\text { protection }\end{array}$ & $\begin{array}{l}\text { Part of main } \\
\text { protection } \\
\text { OR Back-up } \\
\text { protection }\end{array}$ & $\begin{array}{l}\text { Main OR } \\
\text { part of main } \\
\text { protection }\end{array}$ & $\begin{array}{l}\text { Main OR } \\
\text { part of main } \\
\text { protection }\end{array}$ & $\begin{array}{l}\text { Main OR } \\
\text { part of main } \\
\text { protection }\end{array}$ & $\begin{array}{l}\text { Main or } \\
\text { busbar } \\
\text { protection }\end{array}$ & Main & $\begin{array}{l}\text { Main OR } \\
\text { part of main } \\
\text { protection }\end{array}$ \\
\hline Advantages & $\begin{array}{l}\text { Simplicity, } \\
\text { availability of } \\
\text { current mea- } \\
\text { surements }\end{array}$ & $\begin{array}{l}\text { Simplicity, } \\
\text { availability of } \\
\text { voltage mea- } \\
\text { surements }\end{array}$ & $\begin{array}{l}\text { The use of } \\
\text { the first } \\
\text { incident wave } \\
\text { provides high } \\
\text { speed } \\
\text { protection }\end{array}$ & $\begin{array}{l}\text { The use of } \\
\text { the first } \\
\text { incident wave } \\
\text { provides high } \\
\text { speed } \\
\text { protection }\end{array}$ & $\begin{array}{l}\text { The use of } \\
\text { the first } \\
\text { incident wave } \\
\text { provides high } \\
\text { speed } \\
\text { protection }\end{array}$ & $\begin{array}{c}\text { High } \\
\text { selectivity, } \\
\text { directionality, } \\
\text { very robust }\end{array}$ & $\begin{array}{c}\text { High } \\
\text { sensitivity, } \\
\text { directionality, } \\
\text { reduced } \\
\text { transmission } \\
\text { requirements } \\
\end{array}$ & $\begin{array}{l}\text { Very fast, } \\
\text { WT can be } \\
\text { used to detect } \\
\text { singularities }\end{array}$ \\
\hline Disadvantages & $\begin{array}{c}\text { Selectivity } \\
\text { issues, } \\
\text { limited speed }\end{array}$ & $\begin{array}{c}\text { Cannot } \\
\text { distinguish } \\
\text { between } \\
\text { forward and } \\
\text { backward } \\
\text { faults }\end{array}$ & $\begin{array}{l}\text { Protection } \\
\text { margin is } \\
\text { reduced for } \\
\text { very long } \\
\text { lines }\end{array}$ & $\begin{array}{l}\text { Susceptible } \\
\text { to noise, } \\
\text { selectivity is } \\
\text { limited by } \\
\text { low cable } \\
\text { impedance }\end{array}$ & $\begin{array}{l}\text { Susceptible } \\
\text { to noise, high } \\
\text { resistive } \\
\text { faults can be } \\
\text { interpreted as } \\
\text { external }\end{array}$ & $\begin{array}{l}\text { Communication } \\
\text { delays, need } \\
\text { for } \\
\text { synchronised } \\
\text { measurements }\end{array}$ & $\begin{array}{l}\text { Communication } \\
\text { delays, } \\
\text { limitations } \\
\text { against high } \\
\text { resistive } \\
\text { faults }\end{array}$ & $\begin{array}{l}\text { Extensive } \\
\text { simulations } \\
\text { or analysis is } \\
\text { needed to set } \\
\text { the thresholds }\end{array}$ \\
\hline
\end{tabular}

the line length is $200 \mathrm{~km}$, when communication-based fault detection is used [6]. Moreover, communication incurs extra cost, whilst it also causes reliability issues. In [19], the authors achieved to reduce drastically the time delay caused by the communication link but at the expense of installation of extra sensors at various points across the lines. However, current differential can still be used as a means of bus and converter protection [20].

Although single-ended techniques remain in principle nonunit protection methods, they can be used also in closed protection zones, where the signals are communicated to the other end of the line. For instance, wavelet theory is used in [21], to rapidly extract the signs of the currents to use them for directional protection. Wavelet transformation has also been used for a current differential application in [16]. In [10], the current differential method is modified to a travelling wavebased criterion to make the protection algorithm more robust.

The important advantage of non-unit protection methods is that they use only local signals such as currents and voltages to successfully detect a DC fault. In non-unit protection methods, selectivity is ensured with the use of reactors at the ends of each line in order to define specific boundaries A series of simulations is usually needed to demonstrate that the method works as expected and exclusively for all faults within the required protection zone, while remaining idle for external faults. Nevertheless, most of these methods cannot provide individually a sufficient protection system. For instance, in [22], voltage and current derivative are combined to provide a fault detection means.

The reactors at the ends of the lines do not only limit the fault current, but they also behave as natural boundaries for a range of frequencies. Based on this, the voltage signatures are influenced due to the inductive termination of the lines. This important property can assist the discrimination of DC faults and has led to significant research, through which frequency- based nonunit protection schemes for selective HVDC protection have been developed [23]-[27]. These schemes make use of the inductive termination at both ends of a line to define protection zones and divide the system into clear zones. They are based on the concept that inductive termination provides a high impedance path for the high frequency components, thus enabling the comparison of signals before and after the line inductor or alternatively, the use of one of them. However, the right inductor size should be selected according to the DC breaker absorption capabilities, the protection requirements and its interaction with the converter control systems [28].

\section{SYSTEM DESCRIPTION}

In this paper, a four-terminal HVDC test grid as illustrated in Fig. 6, is used for the evaluation of fault detection methods. The test system is modelled in EMTDC/PSCAD simulation tool. The network architecture, the converter parameters and the modelling approach are adapted from [29].The network is operating at $320 \mathrm{kV}$ DC in a symmetric monopolar configuration. The system is comprised of two offshore wind power plants (OWP) that feed two onshore terminals connected to the main AC grid as shown in Fig 6. All the DC lines are modelled as frequency-dependent cables, using the available cables model in PSCAD library. Each converter station is modelled as a half-bridge Modular Multilevel Converter (MMC) technology. The modelling approach for the MMC converters is based on an open-loop control, where the energy stored in each arm is calculated [29], [30]. DC circuit breakers (technology-neutral) are included at the end of each DC line in series with a current limiting inductor $(100 \mathrm{mH})$. Based on realistic theoretical times, the breakers can isolate a fault within 5ms. Converters 1 and 2 are set to control the active power, while converters 3 and 4 employ droop control to control the DC voltage. 


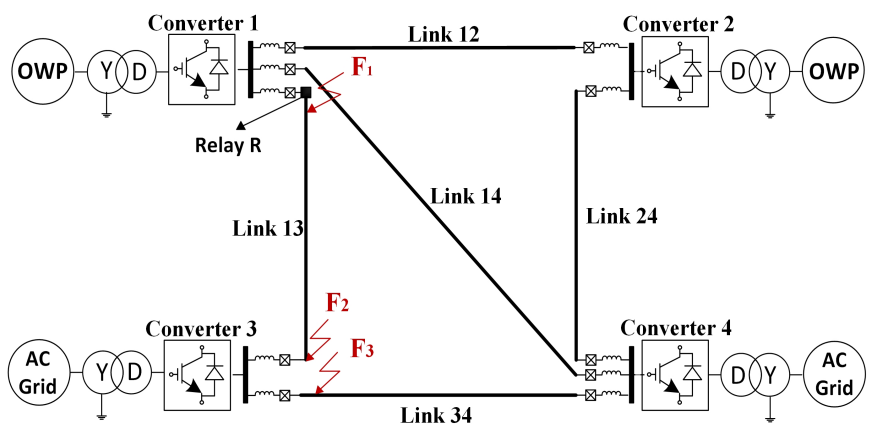

Fig. 2: HVDC test grid model.

\section{Evaluation of DC FAUlt DETECTION METhods}

The discussion section has highlighted that for a large DC network, non-unit protection methods are preferred due to the absence of communication link and the requirement for fast protection. Thus, two fault detection methods that are used in non-unit protection schemes are selected for evaluation: voltage derivative and wavelet transform.

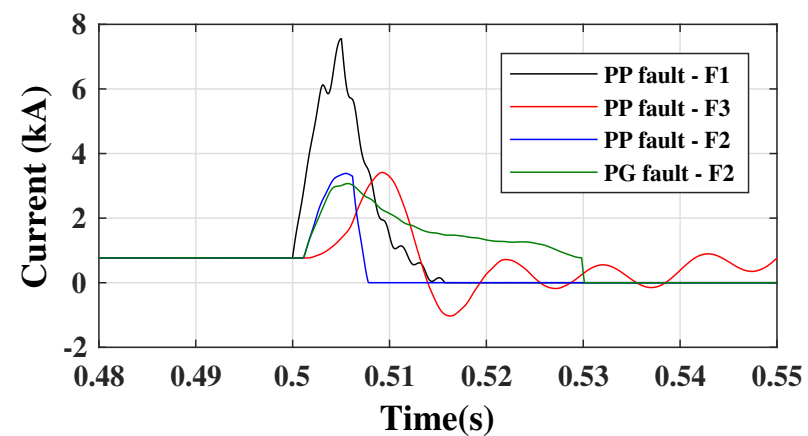

Fig. 3: Fault current profiles.

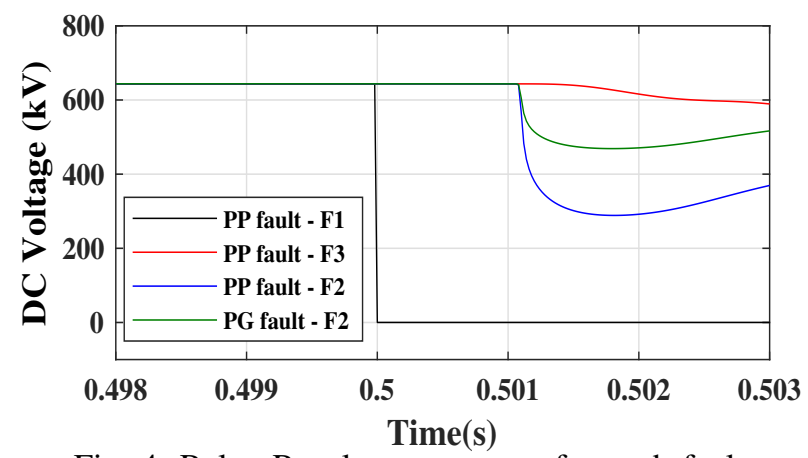

Fig. 4: Relay $\mathrm{R}$ voltage response for each fault.

The investigated methods are evaluated for three different fault locations, i.e. F1, F2 and F3 as shown in Fig. 2. F1 is a solid fault applied at $0 \mathrm{~km}$ of line $13, \mathrm{~F} 2$ is a high resistive fault (100) applied at the end of line $13(200 \mathrm{~km})$ and F3 is a solid fault applied at the start of the adjacent line 34. Currents and voltages are measured from relay $\mathrm{R}$ (shown in Fig 2.). With respect to relay $R, F 1$ and $F 2$ represent internal faults within the boundaries of the relay, while F3 represents an external fault, outside the relay protected area. The protective relay $\mathrm{R}$ should generate a trip command for its associated DC circuit breaker when an internal fault occurs and remain idle after the occurrence of an external fault. Fault F3 with zero fault resistance is selected in order to investigate the performance of the selected fault detection method under the most challenging conditions. The fault current profiles for each fault (faults applied at $0.5 \mathrm{~s}$ ), as measured from relay $\mathrm{R}$ with a breaking action after $5 \mathrm{~ms}$, are shown in Fig. 3. The relay voltages at the inception of the faults are shown in Fig. 4. The time instant that the voltage starts to drop depends on the fault distance.

\section{A. Voltage Derivative}

The abrupt changes exhibited in the voltage at relay $\mathrm{R}$, when the first travelling wave arrives (Fig 4.), can be depicted in voltage derivative. Towards this aim, voltage measurements at relay $\mathrm{R}$ are used to calculate the voltage derivative in a 20s step and the results are shown in Fig 5. For illustration purposes the voltage derivative for fault $\mathrm{F} 1$ is scaled down by a factor of ten. It can be seen that internal faults F1 and F2 produce much higher peaks in voltage derivative and can be clearly distinguished from the external fault F3 where the resulting peak is negligible compared to the former two. Thus, a threshold can be determined through simulations. Fault F1 is detected almost instantly $(0.05 \mathrm{~ms})$, while fault $\mathrm{F} 2$ is detected after $1.1 \mathrm{~ms}$. It should be noted that the impact of the noise and the practical issues regarding digital sampling have not been examined in this study. Digital sampling and noise can influence the reliability, the speed, and the robustness of the protection algorithm. Therefore, further studies are required in order to establish the suitability of the method.

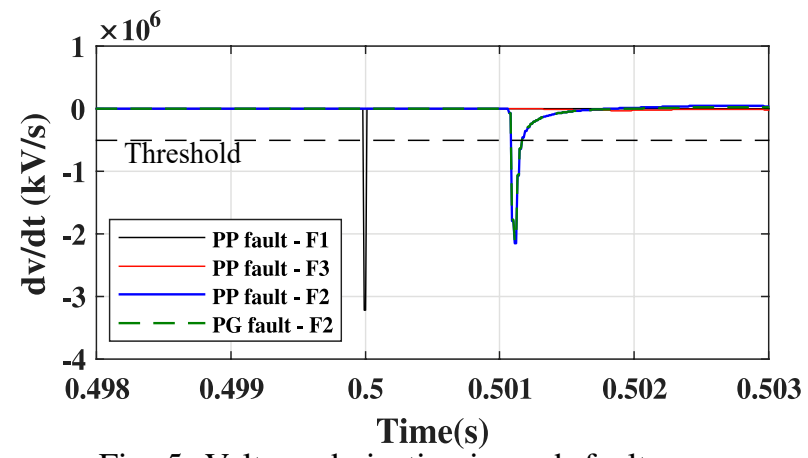

Fig. 5: Voltage derivative in each fault case.

\section{B. Wavelet-based Fault Detection}

One of the most important advantages of the wavelet transform is its ability to detect singularities of a signal. Thus, in case of faults, the WT outputs present local minimum and maximum points. Fig. 6 presents the maximum points of the 6-level WT for each fault when Haar wavelet and DWT is used to detect the fault by observing the travelling waves in the voltage measurements at $100 \mathrm{kHz}$ frequency. A fault is detected when the WT detailed coefficient exceeds a threshold that was set based on simulations. It can be seen that the waveletbased fault detection technique can successfully discriminate between internal faults F1, F2 and the external fault F3. Fault F1 produces a significant WT maximum point and is detected after $0.38 \mathrm{~ms}$ while PP and PG faults at F2 produce lower local maximums and are detected after $1.66 \mathrm{~ms}$. The available margin for the threshold is significantly limited by the PG 
fault (F2) and therefore, the method's performance might be affected in a noisy environment.

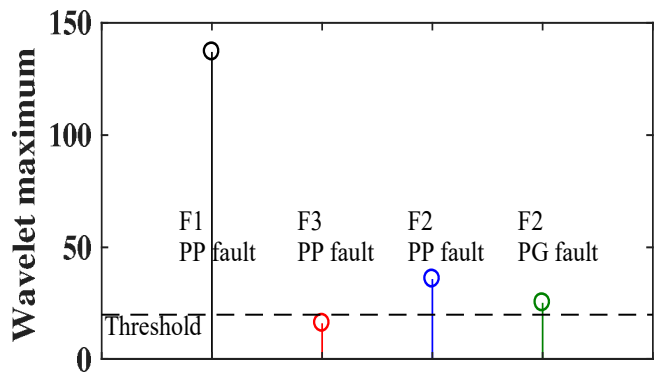

Fig. 6: Wavelet coefficient maximum in each fault case.

\section{CONCLUSION}

This paper has reviewed the state of the art of fault discrimination and detection methods. The fault detection techniques are classified into unit and non-unit protection methods. In non-unit protection, DC reactors are used to form boundaries and enable the protection algorithms to perform successful discrimination between internal and external faults. Voltage derivative and wavelet analysis are recognized as the most promising techniques for fault detection purposes and were chosen for evaluation. The results of the offline simulations of a four-terminal meshed HVDC grid suggest that both methods have facilitated fault discrimination and detection at high speed and their suitability for use in HVDC protection systems, as a main method or a part of a hybrid protection scheme with multiple sub-methods, is established. Further studies on these methods, and the investigation of the impact of other grid parameters such as grid complexity, converter technologies and DC grid and converter control systems on protection schemes, is suggested for future inquiry.

\section{REFERENCES}

[1] S. Le Blond, R. Bertho, D. Coury, and J. Vieira, "Design of protection schemes for multi-terminal hvdc systems," Renewable and Sustainable Energy Reviews, vol. 56, pp. 965-974, 2016.

[2] K. Sharifabadi, L. Harnefors, H.-P. Nee, S. Norrga, and R. Teodorescu, Design, Control and Application of Modular Multilevel Converters for HVDC Transmission Systems. Newark: Wiley, 2016.

[3] CIGRE, "Hvdc grid feasibility study," Working Group B4-52, 2013

[4] S. De Boeck, P. Tielens, W. Leterme, and D. Van Hertem, "Configurations and earthing of hvdc grids," in 2013 IEEE Power \& Energy Society General Meeting, Jul. 21-25 2013, pp. 1-5.

[5] W. Leterme and D. Van Hertem, "Classification of fault clearing strategies for hudc grids," in Proc. Cigre Lund Sym., 2015, pp. 1-10.

[6] D. Jovcic, D. Van Hertem, K. Linden, J.-P. Taisne, and W. Grieshaber, "Feasibility of dc transmission networks," in 2011 2nd IEEE PES International Conference and Exhibition on Innovative Smart Grid Technologies, 2011, pp. 1-8.

[7] M. Wang, M. Abedrabbo, W. Leterme, D. Van Hertem, C. Spallarossa, S. Oukaili, I. Grammatikos, and K. Kuroda, "A review on ac and dc protection equipment and technologies: Towards multivendor solution," in CIGRE Winnipeg 2017 International Colloquium \& Exhibition, 2017.

[8] M. H. Rahman, L. Xu, and L. Yao, "Dc fault protection strategy considering dc network partition," in Power and Energy Society General Meeting (PESGM), 2016, pp. 1-5.

[9] T. An, G. Tang, and W. Wang, "Research and application on multiterminal and de grids based on vsc-hvdc technology in china," in High Voltage, vol. 2, no. 1, pp. 1-10, 2017.
[10] J. Descloux, "Protection contre les courts-circuits des réseaux à courant continu de forte puissance," Ph.D. dissertation, Ph.D. dissertation, Dept. Elect. Eng., Univ., Ph.D. dissertation, Dept. Elect. Eng., Univ. Grenoble, Grenoble, France, 2013.

[11] D. Naidoo and N. Ijumba, "Hvdc line protection for the proposed future hvdc systems," in 2004 International Conference on Power System Technology, 2004, pp. 1327-1332.

[12] B. Chang, O. Cwikowski, M. Barnes, R. Shuttleworth, A. Beddard, and P. Coventry, "Review of different fault detection methods and their impact on pre-emptive vsc-hvdc dc protection performance," High Voltage, vol. 2, no. 4, pp. 211-219, 2017.

[13] M. Ikhide, S. Tennakoon, A. Griffiths, S. Subramanian, H. Ha, and A. Adamczyk, "Limitations of di/dt technique in dc line protection," in 13th International Conference on Development in Power System Protection 2016 (DPSP), 2016.

[14] I. Jahn, N. Johannesson, and S. Norrga, "Survey of methods for selective dc fault detection in mtdc grids," in 13th IET International Conference on AC and DC Power Transmission (ACDC 2017), 2017, pp. 1-7.

[15] K. De Kerf, K. Srivastava, M. Reza, D. Bekaert, S. Cole, D. Van Hertem, and R. Belmans, "Wavelet-based protection strategy for dc faults in multi-terminal vsc hvdc systems," IET Generation, Transmission \& Distribution, vol. 5, no. 4, pp. 496-503, 2011.

[16] D. Tzelepis, G. Fusiek, A. Dyýsko, P. Niewczas, C. Booth, and X. Dong, "Novel fault location in mtdc grids with non-homogeneous transmission lines utilizing distributed current sensing technology," IEEE Transactions on Smart Grid, 2017, doi: 10.1109/TSG.2017.2764025.

[17] Y. Li, Y. Gong, and B. Jiang, "A novel traveling-wave-based directional protection scheme for mtdc grid with inductive dc terminal," Electric Power Systems Research, vol. 157, pp. 83-92, 2018.

[18] C. Troitzsch, A.-K. Marten, and D. Westermann, "Nontelecommunication based dc line fault detection methodology for meshed hvdc grids," IET Generation, Transmission \& Distribution, vol. 10, no. 16, pp. 4231-4239, 2016.

[19] D. Tzelepis, A. Dyśko, G. Fusiek, J. Nelson, P. Niewczas, D. Vozikis, P. Orr, N. Gordon, and C. D. Booth, "Single-ended differential protection in mtdc networks using optical sensors," IEEE Transactions on Power Delivery, vol. 32, no. 3, pp. 1605-1615, 2017.

[20] S. P. Azad and D. Van Hertem, "A fast local bus current-based primary relaying algorithm for hvdc grids," IEEE Transactions on Power Delivery, vol. 32, no. 1, pp. 193-202, 2017.

[21] G. Zou, Q. Feng, Q. Huang, C. Sun, and H. Gao, "A fast protection scheme for vsc based multi-terminal dc grid," International Journal of Electrical Power \& Energy Systems, vol. 98, pp. 307-314, 2018.

[22] J. Wang, B. Berggren, K. Linden, J. Pan, and R. Nuqui, "Multiterminal dc system line protection requirement and high speed protection solutions," in Proceedings of the 2015 CIGRE Symp., 2015, pp. 1-9.

[23] W. Leterme, J. Beerten, and D. Van Hertem, "Nonunit protection of hvdc grids with inductive dc cable termination," IEEE Transactions on Power Delivery, vol. 31, no. 2, pp. 820-828, 2016.

[24] J. Liu, N. Tai, and C. Fan, "Transient-voltage-based protection scheme for dc line faults in the multiterminal vsc-hvdc system," IEEE Transactions on Power Delivery, vol. 32, no. 3, pp. 1483-1494, 2017.

[25] J. Sneath and A. D. Rajapakse, "Fault detection and interruption in an earthed hvdc grid using rocov and hybrid dc breakers," IEEE Transactions on Power Delivery, vol. 31, no. 3, pp. 973-981, 2016.

[26] R. Li, L. Xu, and L. Yao, "Dc fault detection and location in meshed multiterminal hvdc systems based on dc reactor voltage change rate," IEEE Transactions on Power Delivery, vol. 32, no. 3, pp. 1516-1526, 2017.

[27] N. M. Haleem and A. D. Rajapakse, "Local measurement based ultrafast directional rocov scheme for protecting bi-pole hvdc grids with a metallic return conductor," International Journal of Electrical Power \& Energy Systems, vol. 98, pp. 323-330, 2018.

[28] D. Jovcic, W. Lin, S. Nguefeu, and H. Saad, "Low energy protection system for dc grids based on full bridge mmc converters," IEEE Transactions on Power Delivery, 2018, doi: 10.1109/TPWRD.2018.2791635.

[29] W. Leterme, N. Ahmed, J. Beerten, L. Ängquist, D. Van Hertem, and S. Norrga, "A new hvdc grid test system for hvdc grid dynamics and protection studies in emt-type software," in 11th IET International Conference on AC and DC Power Transmission, 2015, pp. 1-7.

[30] L. Angquist, A. Antonopoulos, D. Siemaszko, K. Ilves, M. Vasiladiotis, and H.-P. Nee, "Open-loop control of modular multilevel converters using estimation of stored energy," IEEE transactions on industry applications, vol. 47, no. 6, pp. 2516-2524, 2011. 